\title{
Aesthetic appreciation of landscapes
}

\author{
JIRI BENOVSKY
}

\begin{abstract}
:
In this article, I want to understand the nature of aesthetic experiences of landscapes. I offer an understanding of aesthetic appreciation of landscapes based on a notion of a landscape where landscapes are perspectival observerdependent entities, where the 'creator' of the landscape necessarily happens to be the same person as the spectator, and where her scientific (and other) knowledge and beliefs matter for the appreciation to be complete. I explore the idea that appreciating a landscape in this sense has quite a lot in common with taking and appreciating a photograph. On our way, we will see how imagination plays a crucial role in the story.
\end{abstract}




\section{\$1. Introduction; on the observer-dependence of landscapes}

Appreciating a landscape is a unique aesthetic experience, especially when it comes to strongly scenic landscapes in appropriate light and weather conditions. I will never forget the many hours of my observations of sunrises on the Matterhorn, for instance. This 'perfect mountain' - the most photographed mountain in the world - is best viewed ${ }^{1}$ from Zermatt, at sunrise, when its east face is lit by the rising sun, gradually displaying and emphasizing its unique shape - almost a prototype of what a 'proper mountain' is supposed to look like. Add to this the experience of the wind, the cold ${ }^{2}$, the picturesque clouds, red and orange at this time of the day, and the experience becomes as strong and overpowering as any aesthetic experience can be.

In this article, I want to better understand the nature of this type of aesthetic experiences. I offer an understanding of the appreciation of landscapes based on the idea that landscapes are perspectival entities (relative to an observer), where the 'creator' of the landscape necessarily happens to be the same person as the spectator, and where her scientific (and other) knowledge and beliefs matter for the appreciation to be complete. I explore the idea that appreciating a landscape in this sense has quite a lot in common with taking and appreciating a photograph. On our way, we will see how imagination plays a crucial role in the story.

To start, it is important to avoid a possible confusion. Indeed, in what follows, I am only going to focus on the appreciation of landscapes, especially of scenic mountainscapes, and not on the aesthetic appreciation of nature in general. This restriction of the scope of my claims matters a great deal. First, nature is a much more inclusive thing than a landscape. Nature includes animals, ecosystems, bacteria, microscopic structures of plants, galaxies, planets, etc. - all of which can be subject to aesthetic appreciation, but which cannot be said to be part of a landscape, at least not in normal cases where, for instance, the microscopic structure of a plant or a rock cannot be seen simply because it is too small to be perceived by an ordinary subject while she is appreciating a landscape (similarly for the rings of Saturn, too far to be seen in such viewing conditions, and so on). Second, while in this article I will go along with the idea that nature exists out there in the world (that is, the idea that mountains, rivers, glaciers, etc. exist in the world independently of a subject, leaving aside, for the

\footnotetext{
${ }^{1}$ See Figure 3 in $§ 3$ below and the discussion there.

${ }^{2}$ In this article, I will focus on the visual aspect of experiences of landscapes, which I take to be the most important.
} 
purpose of this article ${ }^{3}$, eliminativism about such macroscopic objects), the first thing to note about landscapes is that they do not exist in the world as entirely observer-independent entities. Again, this is not a general claim stemming from the ontology of mountains, rivers, or glaciers. Rather, it's the idea, specific to landscapes, that the observer plays a crucial role in the coming into being of landscapes qua objects of aesthetic experiences, which are not understood here as mere collections of mountains, rivers, glaciers, and so on. Rolston (1995, p.375) says that "Aesthetic experience of landscapes is not some pre-existing characteristic of the landscape that is found, but one that emerges when persons react to landscapes." He speaks here about the experience of landscapes, and of course any experience, being an experience, is a subjective affair. But the idea here carries over to the landscapes themselves, I think. In this article, I thus propose to explore a notion of a landscape, where landscapes are understood as perspectival entities, and where they are not the same thing as nature. I suggest keeping the term "nature" for what there is out there in the world independently of any observer (the mountains, rivers, glaciers, and collections and arrangements of those), and using the term "landscape" to refer to something else - namely, something that requires at least a point of view and a framing. We humans have a perceptual system that allows us to see with an angle of view of roughly $60^{\circ}$. Thus, if we are standing at a location and when we are looking at a piece of natural environment in front of us (say, the Matterhorn and its immediate surroundings), we see a delimited - framed - portion of it, which we have selected to look at (we can move our eyes or our bodies to select another framing or a different point of view ${ }^{4}$ ). Once we have selected the point of view and the framing, we are thus, as Rolston (p.376 and 380) puts it "the landscape architects" - as he says, "[1]andscape comes into being in the

\footnotetext{
${ }^{3}$ This article is not concerned with the ontology of macroscopic ordinary objects. When it comes to this ontological issue, I do happen to be an eliminativist of this kind. Various versions of such a type of eliminativism can be found, for instance, in Unger (1979), Van Inwagen (1990), Merricks (2001), and Heller (1990, 2008).

${ }^{4}$ In this article, for simplicity and brevity, I will not discuss the dynamic and temporally extended aspect of an aesthetic experience of a landscape. Clearly, a landscape continuously changes, as clouds or the sun move for instance, and this is often a relevant aspect of the experience. I will briefly mention this aspect several times in what follows, but I will not provide a full analysis of it. As it will become apparent in §5 below, I think that appreciating a landscape has a lot in common with the way we appreciate a photograph. On the way photographs (can) depict/represent temporal extension see Benovsky (2012a). There are some interesting similarities there with what I say here, especially when it comes to the role imagination plays in the appreciation of photographs (and landscapes). In Benovsky (forthcoming), I discuss how our experience of change, movement, temporal extent, and the passage of time works, based on the idea that such dynamic experiences arise from the way our brain interprets appropriately connected static events (see also Paul (2010)).
} 
human interaction with nature." A landscape is thus understood here as a perspectival (one could say, partly mind-dependent and relational) entity that comes into being when an observer - a subject with a point of view and a restricted framing - perceptually interacts with a piece of nature. Granted, this is perhaps a rather technical sense of "landscape", probably not matching the ordinary use of this word (the ordinary use often takes "landscape" to mean something close to "piece of nature"). But we need such a specialized and somewhat technical term if we want to understand a certain kind of aesthetic appreciation of landscapes, where it is such a perspectival entity that we appreciate aesthetically, and not a piece of nature. The perspective, point of view, and framing are absolutely crucial (figure 3 in $\S 3$ below is a good example of that) to this kind of aesthetic experience, and insisting on this issue in the way I do will allow me to make sense of the way this type of appreciation works. Thus, what I do in this article is to explore the consequences of one plausible hypothesis about what a landscape is. In short, I take this notion of a landscape qua perspectival entity on board - while of course other notions could be available - and I try to see where it leads.

§2. On the distinction between 'simple' and 'informed' appreciation of landscapes (and on awe and wonder)

An experience of landscapes, especially of very scenic landscapes in good viewing conditions, is often compared to an almost religious experience. Indeed the wonder and awe one can feel in such a situation are very strong and one often 'feels small' ${ }^{15}$ (in the case of, say, a scenic mountainscape such as the Matterhorn), in a very emotional and agreeable way. It is no surprise that landscapes, and especially mountainscapes, have given rise to many naïve popular pseudo-religious or religious beliefs - mountains have been said to be sleeping giants, or having been made by giants, or being inhabited and/or made by God(s), for instance. Thus the wonder and awe one feels here is not only due to the landscape itself but also in a significant part to its alleged origin. One 'feels small' because the creator(s) of such things as mountains must have been very powerful indeed (or because the mountains - if they are sleeping giants - are so big and powerful).

\footnotetext{
${ }^{5}$ Compare to the classical notion of the sublime (see inter alia Burke (1757), Kant (1790), Schopenhauer (1818)).
} 
This is perhaps where one can find a starting point or a first motivation for the sciencebased view of aesthetic appreciation of landscapes (see, inter alia, Rolston (1995), Carlson (1981, 2000), and Parsons (2002), who speak mainly about nature, and not about landscapes). The idea is this: given enough information from science, especially, when it comes to mountains, from geology, geography, glaciology, or climatology, one gets to know what the origins of a landscape - say, the Matterhorn - are, and one can appreciate the enormous forces and the huge amount of time it took nature to produce such an object. When it comes to the awe and wonder one can feel, the doings of giants or God(s) are replaced here with the 'doings' of nature, the erosion, the movements of tectonic plates, the slow movements of the glaciers, and so on. Understanding these natural processes amounts to understanding the origins of what one is looking at, where the process of creation of a mountain can be actually as impressive as the mountain itself.

Of course, many other types of information, science-based or not, can play a significant role here. For instance, the knowledge that the Matterhorn is 4'478 meters high, which makes it one of the highest peaks of the Alps, can also contribute to the way it is appreciated. (One can 'feel small' here again.) Or perhaps, information an alpinist has about the difficulty of climbing the Matterhorn's north face can make a further contribution to the way she will look at it and appreciate it (here again, one can 'feel small' by considering how hard it is to do the climb). Thus, an important distinction to be made here is one between a 'simple' and an 'informed' appreciation of landscapes. A simple aesthetic appreciation of a landscape is an appreciation mostly of its shapes and colours; as Carroll (1993, p.245) - who speaks about nature in general and not only about landscapes - puts it, it is an appreciation "[...] of a less intellective, more visceral sort, which we might refer to as 'being moved by nature"'. Sometimes, and perhaps more often than not, this is indeed how we aesthetically appreciate a landscape. A sunrise on the Matterhorn seen from Zermatt is a good example: if the weather conditions are good, its unique shape is faintly observable against the sky in the dark, only lit by the moon, and then is made gradually more and more visible by a slowly descending orange and beautiful light, first illuminating its summit and then progressively illuminating its entire shape, while its surrounding are still in the dark ${ }^{6}$. One can then simply appreciate the shape and the colours, in a very simple and 'visceral' way, as illustrated by the two following photographs (All photographs used as illustrations in this article can be seen in colour and

\footnotetext{
${ }^{6}$ A time-lapse video of this can be seen at http://www.jiribenovsky.org/aesthetics-landscapes.
} 
higher resolution here: www.jiribenovsky.org/aesthetics-landscapes. Copyright by the author.):

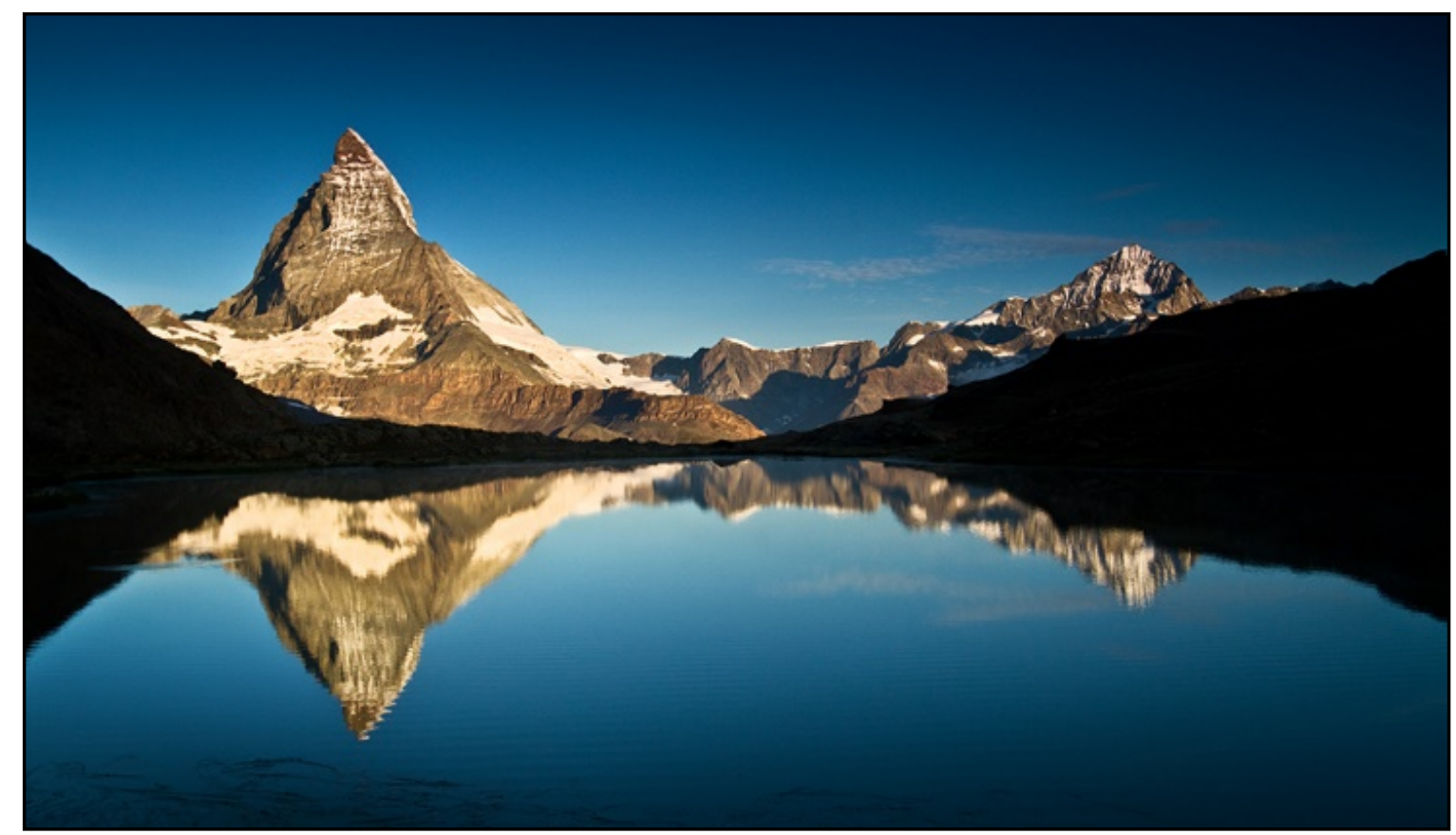

Figure 1. Matterhorn, reflection in the lake Riffelsee.

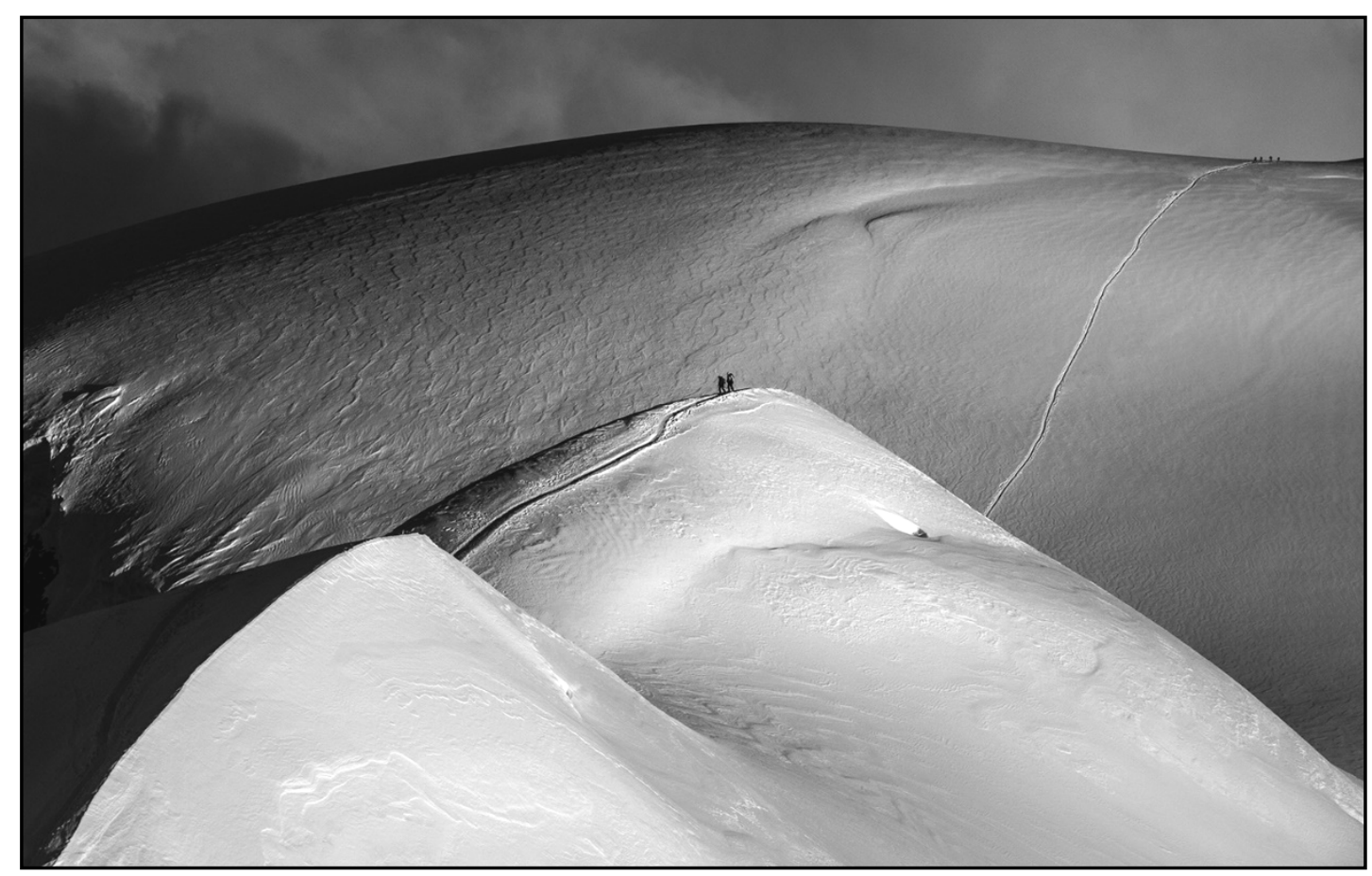

Figure 2. L'arête des Bosses ("The Ridge of Bumps"), on the way to the Mont-Blanc. 
These two landscapes exhibit several of the properties one is often looking for in an artwork, say a painting or a musical work, such as symmetry, balance, harmony, as well as 'simply beautiful' shapes, colours, and contrasts. As in the case of an appreciation of artworks such as paintings or musical works, the observer's taste will manifest itself here to judge what is more or less beautiful. Some appreciate simple desert landscapes (and will perhaps appreciate the landscape illustrated by Figure 2), while others will perhaps be more strongly moved by the symmetry of the reflection in the lake of the landscape illustrated by Figure 1 . This simple, immediate, 'visceral', emotional, and non-intellective appreciation of a landscape is a subjective affair, not only because as we have seen any landscape is a perspectival entity, but also because it is the 'first reaction' to a landscape we look at.

An informed appreciation of a landscape, on the other hand, contains a lot of objective components. Knowing that the landscape illustrated by Figure 2 is an erosion-shaped glacier, not far from the summit of the Mont-Blanc, the highest peak of the Alps, certainly adds to the appreciation we can have of it. Perhaps, knowing how rare a sight the landscape illustrated by Figure 1 is - since it has to be observed at a very precise time after sunrise in conditions where there are no clouds and no wind at all, and at the right time of the year - can also augment its overall appeal. Many other types of information, coming from science, alpinism, or other sources can come into play.

Thus, it seems that the 'simple' appreciation of landscapes is more subjective, while the 'informed' appreciation is more objective. But this does not mean that there is an opposition between the two - one being subjective and the other being objective. On the contrary, they usefully complete each other: the informed appreciation will (or at least, can) come to enrich and supplement the subjective one to make the overall aesthetic experience of the landscape stronger and more complete (this is similar to the way knowledge of the origins and context of creation of, say, a painting or a novel, can enrich our appreciation of it). Thus, scientific and other knowledge helps to expand our aesthetic appreciation of landscapes, rather than impoverishing it by 'objectifying' it'?

\footnotetext{
${ }^{7}$ An often-cited example of such a case is Hepburn's (1963, p.200): "Supposing I am walking over a wide expanse of sand and mud. The quality of the scene is perhaps that of wild, glad emptiness. But suppose that I bring to bear upon the scene my knowledge that this is a tidal basin, the tide being out. I see myself now as virtually walking on what is for half the day sea-bed. [...] Thus, in addition to spatial extension (or sometimes instead of it), we may aim at enriching the interpretative element of our experience, taking this not as theoretical 'knowledge-about' the object or scene, but as helping to determine the aesthetic impact it makes upon us."
} 
The way the informed enrichment of a simple appreciation works is largely due to the role imagination plays in aesthetic appreciation, in the case of landscapes as well as in general. The idea here is that information coming from science or from other sources activates and nourishes our imaginative capacities. This is nicely illustrated by the 'information' that mountains are, say, sleeping giants, or by information about the level of difficulty of climbing Matterhorn's north face (where one can imagine oneself in the situation of doing the climb, for instance). Information from science can encourage our imagination to, for instance, visually imagine as an accelerated movie the movements of the glaciers or the movements of tectonic plates. But even less scientific and more ordinary information from simple folk observations of nature can play this role: for instance, when one looks at the Matterhorn and its surroundings in summer, one can imagine what it could look like in winter, entirely covered in immaculate white snow, and perhaps judge it to be even more beautiful than the summer landscape, without ever actually seeing it. Our imagination is thus triggered and enriched by information, scientific and/or other, and this then allows us to have a more complete and stronger aesthetic experience of the landscape. Again, there is no tension between a subjective 'imagination approach' of the aesthetic appreciation of landscapes and a more objective 'science-based approach' - on the contrary, the latter completes and enriches the former (contra Brady (1998), see Fudge (2001) for a discussion).

Landscapes and the information we have about them actually play the role of props that stimulate imagination to produce an aesthetic experience, in a way similar to how Walton (1990) analyses the way pictures depict by being props in games of make-believe. In Walton's view, when children play and imagine tree stumps to be bears, they are creating a fictional world of the game, where it is true that tree stumps are bears, because it was decided in an imaginary - but controlled - way, that tree stumps represent bears. In the case of aesthetic appreciation of landscapes, there is the 'simple' perception and appreciation of it, but as we have seen there is also the possibility of imagination playing an important role, based on the landscape itself and on additional information, where one can create a fictional world where mountains are giants, or where one is climbing Matterhorn's north face, or where time speeds up and we actually see glaciers moving and mountains rising due to the accelerated movements of tectonic plates. This controlled imagination can be subject to new additional information and can be modified every time one learns something new about the landscape. Again, the Matterhorn is a good example. Standing in Zermatt at sunrise and observing this 
incredibly pointy peak, one can feel thrilled by imagining what it must be like to stand on its top - how vertiginous this must be! But then, say that you actually climb up the Matterhorn, by the very route that can be seen from Zermatt (the Hörnli ridge), and you realize that most of the ascent is actually done by walking, and involves only relatively easy climbing parts, and that the summit is large enough for at least twenty people to sit there and have a picnic - a much less impressive and vertiginous experience than what one would have thought! You then realize that the Matterhorn is much more impressive and much more beautiful from a Zermatt café than when one actually climbs on the top of it - the imagination that the Matterhorn triggers, when viewed from the proper angle from the valley, is just much stronger and richer than reality. This can be seen either as a frustrating experience where the climbing of the Matterhorn actually takes away some of its beauty, or on the contrary it can be seen as a way to emphasize how beautiful it is as seen from the valley - one becomes even more sensitive to this landscape, viewed from a point of view located in the valley, at the right angle.

One thus realizes how important the framing and the point of view are (indeed, as I have emphasized above, they are part of what a landscape is, since it is a perspectival entity), as illustrated by the following Figure:
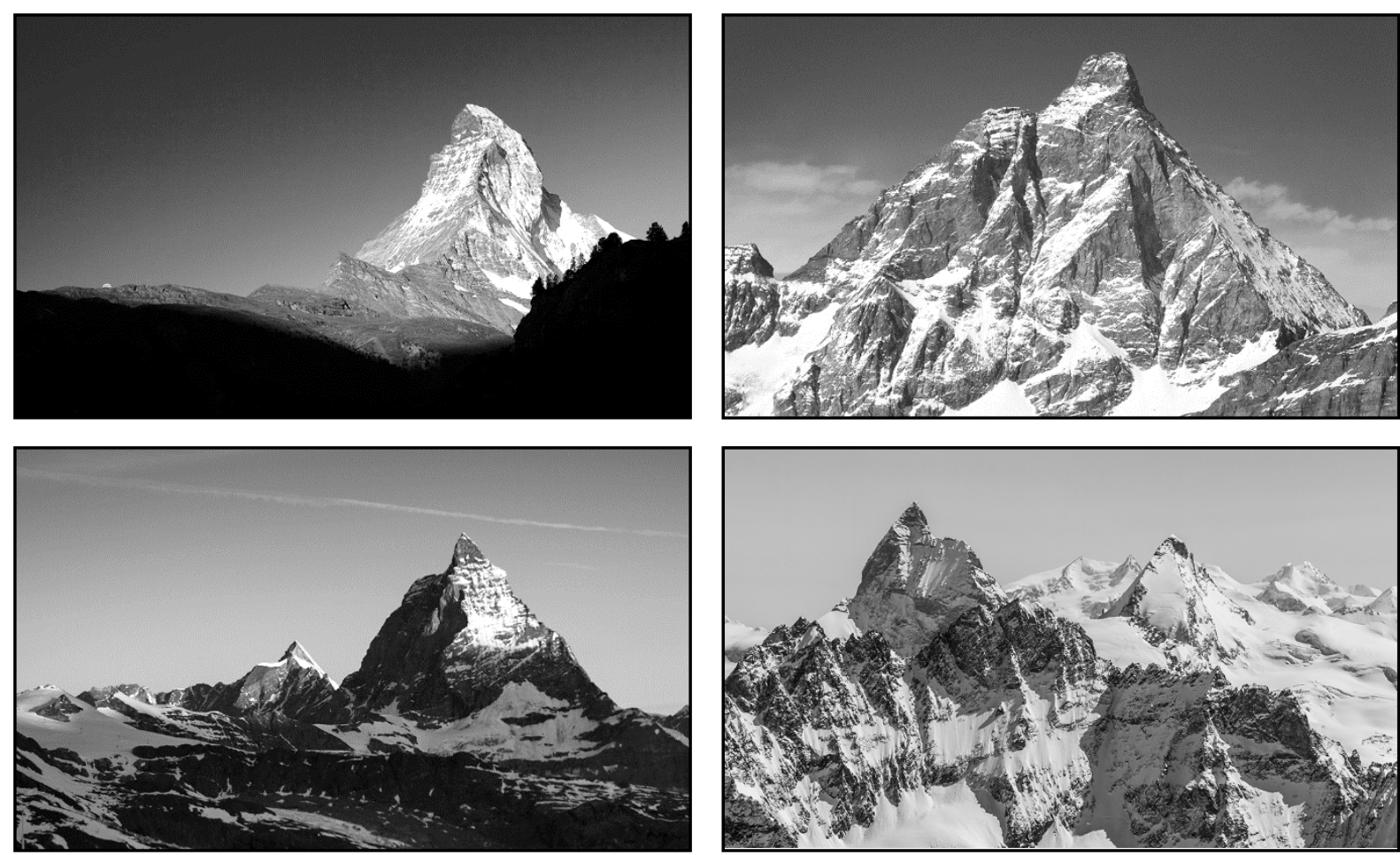

Figure 3. Matterhorn, seen from (i) Zermatt, (ii) Cervinia, (iii) Monte Rosa Hut, (iv) Pigne d'Arolla 
The first two illustrations are perhaps the most telling - the Matterhorn seen from Cervinia (the Italian side) is clearly far from being as beautiful as it is seen from Zermatt. Under the understanding I offer of landscapes, these are two numerically different landscapes, each with its own aesthetic properties grounded in different non-aesthetic properties (simple or coming from additional information), and each triggering imagination in a different way.

\section{§4. What makes an informed appreciation to be aesthetic?}

I have insisted on the role imagination plays (or at least can play) in the appreciation of landscapes, and on the role information plays (or at least can play) as well. I have said that an informed appreciation of, say, the Matterhorn is richer and stronger than a simple one. Now, one could agree with all this but still object that this informed appreciation is not an aesthetic one. One could think that values attributed to a landscape based on information coming from science, alpinism, etc. are intellectual values, not aesthetic ones.

As a reaction to this legitimate worry, I suggest to simply observe that the informed (and imagination-nourished) appreciation of landscapes has all the typical characteristics of an aesthetic appreciation - thus, there simply is no reason to think that it is not genuinely aesthetic. At the level of simple appreciation, as we have seen, landscapes exhibit typical features artworks can have, such as unity, simplicity, harmony, or symmetry. These features can be found at the informed level as well, albeit in a different way. For instance, the sciencebased and imagination-nourished accelerated movements of the glaciers, flowing around the Matterhorn and shaping it, can possess this type of features. Or, to take an alpinism-informed example: a particular route to climb Matterhorn's north face can also be appreciated as being particularly harmonious, with a constant level of difficulty, involving elegant climbing moves that have to be made, and the line itself, as projected in an imaginary way on the mountain when viewed from the valley, can have a symmetry, harmony, simplicity, and elegance of its own.

When it comes to the way we talk about landscapes, not only the simple appreciation but the informed appreciation as well typically give rise to statements of aesthetic judgements. A landscape is often said to be beautiful, and even more so when information of the kind mentioned above is added.

Also, and quite importantly, exactly as a simply appreciated landscape, a landscape appreciated in an informed and imagination-enriched way has the capacity to cause passion 
and emotion - to borrow Hume's way to put it, such a landscape is fully "fitted to give a pleasure and satisfaction to the soul" (Hume (1975, p.299)). Fudge (2001, p.277, my italics) insists - rightly - on this point: "But why suppose that this [informed, science-based] appreciation is aesthetic, rather than strictly scientific? [...] For our purposes, it is sufficient to mention two themes that commonly appear in accounts of aesthetic experience. The first of these is the delight we take in perceiving or conceiving of an aesthetic object. [...] [The second] states that aesthetic experience is characterized by a kind of 'detachment' or losing oneself in contemplating the aesthetic object. There is an active engagement with the object, which excludes everything external to it. [...] The important point is that delight and detachment are not necessary components of scientific appreciation." (Fudge speaks about nature, and not specifically about landscapes.) As before, we can have in mind here examples of the accelerated movements of glaciers, or of information about an elegant climbing route. Other possible examples could include, for instance, the information that a mountain, say the Grand Capucin ${ }^{8}$, an enormous monolith in the Mont-Blanc area, is made a of very highquality red granite, a type of rock that can be appreciated both by the geologist and by the climber (for different reasons, of course) - one can find here beautiful the fact that the Grand Capucin is such a huge piece of perfect granite $^{9}$, as much as one can appreciate this type of information about a granite statue, such as the colossal red granite statue of Amenhotep III, exhibited in the British museum. The knowledge about the homogeneity and perfect microstructure of such a high-quality rock can thus augment the "delight" and the "pleasure and satisfaction to the soul" that both the mountain and the statue can give the spectator (or the alpinist). (Of course, the structure of this type of granite that is visible to the naked eye when viewed from a close distance can be a subject of simple aesthetic appreciation as well. But when one observes a landscape, one is usually not close enough for this to play any role in the appreciation of the landscape.)

In general, landscapes have in common with all objects of aesthetic appreciation that their aesthetic properties are grounded ${ }^{10}$ in their non-aesthetic properties. These non-aesthetic properties of course include the sensory properties one gets from a simple appreciation of a landscape, but they can also include non-sensory properties based on additional information, knowledge/beliefs, and imagination. Granted, the sensory properties are necessary and the

\footnotetext{
${ }^{8}$ See a photograph of the Grand Capucin at www.jiribenovsky.org/aesthetics-landscapes.

${ }^{9}$ The Matterhorn is not a good example here; it is composed of various sedimentary rocks and gneisses.

${ }^{10}$ The grounding relation is better suited that supervenience to explain the relationship between aesthetic properties of an object and its non-aesthetic properties. For a detailed discussion, see Benovsky (2012b).
} 
additional properties are probably not. But this does not prevent these additional non-aesthetic properties to enrich the appreciation of a landscape in such a way that the resulting overall appreciation of it is aesthetic - thus, a landscape's aesthetic properties are necessarily partly grounded in its non-aesthetic sensory properties, and contingently partly grounded in its nonaesthetic information-and-imagination-based properties. A landscape's sensory properties are a necessary starting point, but they do not (have to) exhaust the basis for an overall aesthetic experience.

Similarly as in the case of works of art such as paintings, novels, or musical works, we have already seen above that the taste of the spectator and the origins (the creation) of a landscape (can) play a significant role in its aesthetic appreciation. Exactly as in the case of artworks, a quality evaluator is needed. For instance, one must be careful to use one's imagination in an appropriate way, for there is the risk that instead of enriching the appreciation of the landscape it can actually divert our attention from it - say, if I look at the Matterhorn, and this makes me imagine it as a Toblerone, which in turn makes me think of chocolate, which makes me think of my two years old son and the chocolate stain he made on the sofa yesterday. Imagination (exactly as in the case of paintings in Walton's view) has to be controlled and guided in a careful and relevant way ${ }^{11}$. Thus, taste and the use of imagination are to be understood here as rather sophisticated capacities - as Hume would say, not everybody's taste counts $^{12}$, and not everybody is a good critic of art ... and a good appreciator of landscapes.

To sum up:

- Landscapes can possess features such as unity, simplicity, harmony, and symmetry, both under a simple and an informed appreciation.

- Landscapes are often said to be beautiful, both under a simple and an informed appreciation, by competent appreciators.

- Landscapes can cause appropriate emotional responses in their spectators, both under a simple and an informed appreciation.

- The aesthetic properties of landscapes are well-understood as being grounded in their non-aesthetic properties - sensory, informed, and imagination-based.

\footnotetext{
${ }^{11}$ Brady (1998, p.143-144) makes an interesting distinction here between four kinds of imagination - ampliative, revelatory, exploratory, and projective - and the various ways it can play a role in the aesthetic appreciation of nature (and not only landscapes).

12 Hume (1985, p.240-241) also adds that such qualified judges also have to be practiced in the attribution of aesthetic properties, have to have a "good sense", and have to be intellectually honest.
} 
- The origin (the creation) of a landscape can matter for its appreciation.

- The taste of the spectator of a landscape matters for its appreciation.

- Imagination plays a crucial role in the appreciation of landscapes.

Thus, landscapes behave in a way that is relevantly very similar to other objects of aesthetic appreciation, and the natural thing to conclude here is then simply to accept that the appreciation one has of landscapes - both simple and informed - is genuinely aesthetic.

\section{§5. On landscapes and photographs}

Given the crucial role imagination and information play in aesthetic appreciation of landscapes, I would like to offer now an understanding of such an appreciation of landscapes where appreciating a landscape has some relevant similarities with the appreciation of a photograph. There are at least four relevant points of similarity between landscapes and photographs:

(i) Landscapes, like photographs, come into existence in an observer-dependent way - no observer, no landscape; no photographer, no photograph ${ }^{13}$.

(ii) Landscapes, like photographs, are framed and taken or observed from a point of view, at a specific time.

(iii) Both landscapes and photographs (unlike paintings) always involve the existence of something in the world.

(iv) Landscapes, qua observer-dependent entities, are transparent, in a sense very similar to photographs.

(v) Attention management techniques are central to photography, and play an important role in the appreciation of landscapes as well.

\footnotetext{
${ }^{13}$ This is true in all normal cases. The case of a photograph taken by accident if a camera drops on the floor and the shutter is released does not constitute a relevant counter-example, but I do not have the space here to defend this claim, based on the idea that in all cases, including the case of the camera that falls on the floor, decisions need to be taken, necessarily, before a photograph comes into being (I discuss this issue in Benovsky (2011) and more quickly but more specifically in Benovsky (2014, §5)).
} 
In this section, I will briefly discuss (ii), (iii), (iv), and (v). Concerning (ii), similarly as in the case of photographs, not only the point of view and the framing are crucial and constitutive of what a landscape is, but the time of observation - that is, the time of creation of a landscape is a necessary ingredient of any landscape's coming into existence and its aesthetic appreciation. Indeed, light and weather are absolutely central to what a landscape looks like, as illustrated by the following Figure:

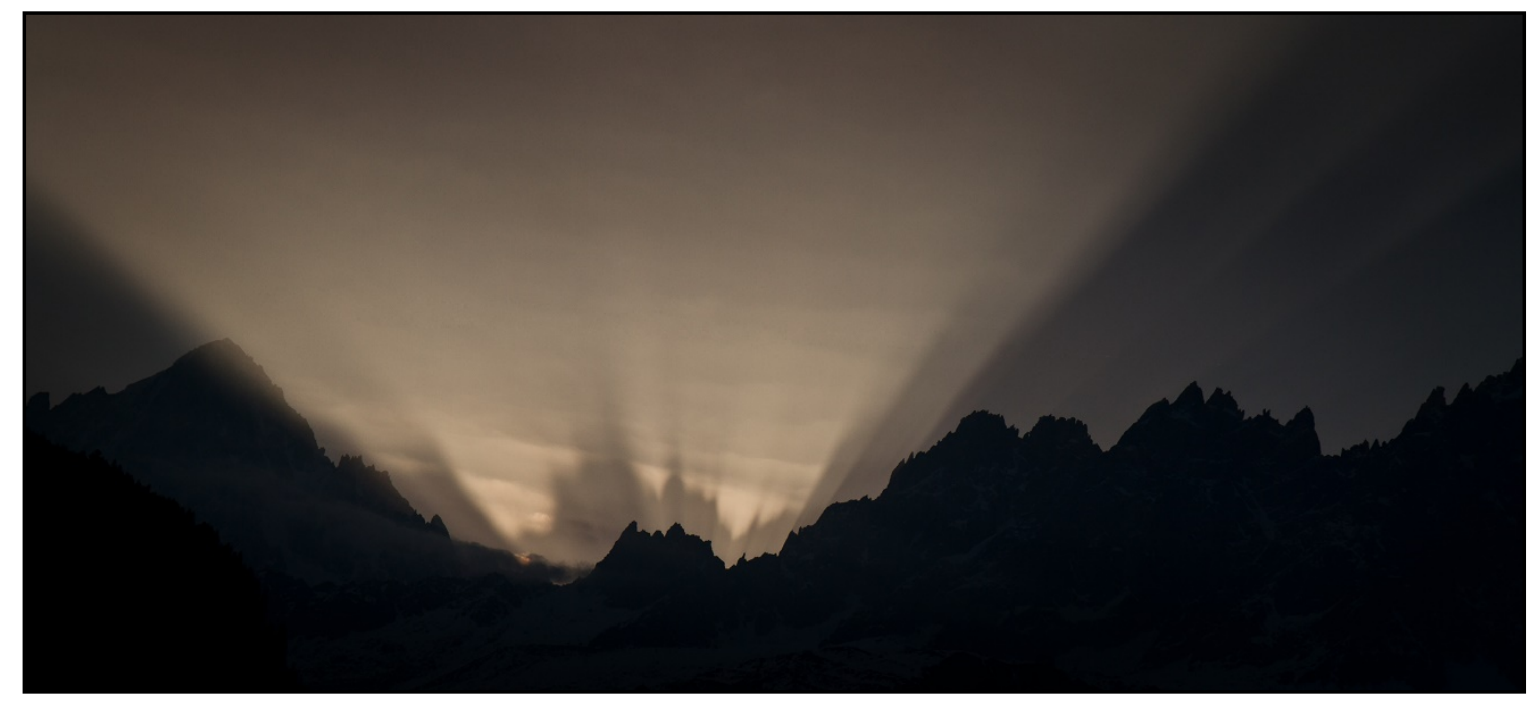

Figure 4. A Brocken spectre.

This photograph shows the mountains above Chamonix, France, at a very special time, when the rising sun casts the shadow of the mountains on the surface of the clouds. Clearly, when observed an hour later, the landscape is a completely different affair. When it comes to the aesthetic appreciation of both the landscape and the photograph, the time at which it was observed/taken is absolutely crucial - indeed, in this case, it is the main thing that makes it aesthetically interesting. Thus, aesthetic properties of landscapes, like aesthetic properties of photographs, are relative to a framing, a point of view, an observer, and the time of observation (all of these should be included in the basis in which the aesthetic properties are grounded). This is how the context of creation of landscapes and of photographs can be 
understood $^{14}$. (Of course, some of these similarities can also, at least partly, concern other types of aesthetically appreciated objects, such as for instance paintings ${ }^{15}$.)

Photographs, unlike other types of depictive entities (relevantly, unlike paintings), are always photographs of something existing (at the time of the creation of the photograph). Even a blurred, distorted, black-and-white photograph is always, in virtue of the nature of what a photograph is and how it comes into being, a photograph of something (something that reflects light recorded by the camera) ${ }^{16}$. Hallucinations set aside, a landscape, even understood as a perspectival observer-dependent relational entity, also always involves the existence of something, say, the existence of the Matterhorn.

In a sense, landscapes share with photographs the transparency feature, as Walton (1984) calls it in the case of photographs. Walton claims that photographs allow us to literally see the objects they depict - they are, then, transparent. I am not going to defend Walton's view about photographs here (I do so in Benovsky $(2011$, §5) where I defend the transparency thesis, albeit for reasons that differ from Walton's own), I am simply going to take it on board, as controversial as it is. The idea is then this: when we see a photograph of the Matterhorn, given the transparency thesis, we see the Matterhorn itself. When we look at the Matterhorn and we appreciate the resulting landscape, we see the Matterhorn itself as well - framed and all, as we have already seen. This is how an appreciation of the landscape and of the photograph are so close to each other, when it comes to the transparency thesis. (Of course, it is crucial to keep in mind here that the landscape is not just the mountain. The mountain is out there in the world, it is a piece of nature. The landscape is a perspectival observer-dependent entity.)

Finally, an important feature of photographs to be insisted upon is that, like in the case of paintings or other works of art, the spectator of a photograph is guided par the artist. The artist's intentions, when the work is successful and correctly appreciated, guide the imagination ${ }^{17}$ and the overall appreciation of the spectator of the work. In the case of

\footnotetext{
${ }^{14}$ The context of creation matters in the aesthetic appreciation of all works of art (see, inter alia, Walton (1970), or Levinson (1984, p.93-94)), and it can typically include historical, political, or social contexts (think, for instance, of Kundera's "The Joke").

${ }^{15}$ In Benovsky (2013), I explore and defend the view that photographs and paintings are not as different as one might think.

${ }^{16}$ Levinson (2015, p.168): "A photograph is always in some degree and at some level a trace of something real, something that exists or that existed at some time [...]."

${ }^{17}$ On the (central) role imagination plays in photographic depiction and representation, see Benovsky (manuscript).
} 
photographs, this guidance is a particularly salient and important point, which I discuss in detail in Benovsky (2012a, §2-3); let me shortly sum it up here. The point is about attention management. For instance, the photographer can purposefully guide and control the attention of the spectator by deciding where she will look first and where she will look next, thus deciding the order in which she sees things, using tools such as the choice of depth of field, the choice of exposure of the main subject comparatively to its surroundings, the composition of the photograph, or the relative size of the main subject to its surroundings. The photographer makes here some intentional choices, creating a photograph that will make some of the depicted elements more perceptually salient than others. When doing this, the photographer exploits the natural tendency of our perceptual system to, for instance, first look at what is sharp and only then at what is blurred (probably because what is sharp provides more information). Exploiting this natural perceptual tendency, when the photographer makes a choice of, say, a shallow depth of field, she then effectively guides the spectator's attention, literally forcing her to look at a specific part of the photograph rather than another - the natural tendency of a perceptual system of any normal observer will make her look first at what is sharp and only then at what is blurred.

Of course, when it comes to landscapes, there is no such thing as a choice of depth of field (although when one focuses on a specific part of a landscape, the remaining parts of the landscape are perceived in a less sharp way, since our field of vision is not uniformly sharp, so perhaps this could be understood in a parallel way). But clearly, the choice of a point of view, the choice of the time of observation, and the framing, are ways to guide one's appreciation of a landscape, exactly as in the case of photographs. The photographer chooses such-and-such a framing because she wants her spectator to look at such-and-such a thing and focus on it. The same is true about landscapes. The observer chooses a point of view, a time, and a framing, which are the best suited for appreciating a landscape (turning in the opposite direction, say, would have the opposite effect). Now, of course, the one who makes these choices and the one who benefits from them is, in the case of landscapes, always and necessarily the same person (telepathy set aside) - unlike in the case of photographs where the observer can be a different person than the author. The idea I want to put forward here is then that appreciation of landscapes and appreciation of photographs do work in interestingly 
similar ways, with the relevant observation that in the case of landscapes the 'artist' and the spectator are one and the same person ${ }^{18}$.

\section{§6. Positive aesthetics for landscapes?}

In the preceding sections, I offered an account of aesthetic appreciation of landscapes based on the idea that landscapes are perspectival observer-dependent entities, and that their appreciation often importantly involves imagination and belief/knowledge. I have also argued that there are some interesting similarities between landscapes and photographs, with the difference that in the case of landscapes the artist and the spectator are necessarily one and the same person. But, the two roles - the artist's and the spectator's - can be conceptually distinguished, even if the person playing the two roles is necessarily the same. This latter claim, taken together with the other points of the overall view I am offering, has an interesting consequence when it comes to the "positive aesthetic" thesis (see, for instance, Carlson (1984)). This thesis is usually a claim about aesthetic appreciation of nature, and not of landscapes in my sense, but it could very well be adapted to the case of landscapes as well. To put it briefly, the idea is that nature (or landscapes) always has positive aesthetic properties and never negative ones - in short, nature is always beautiful, never ugly. One can easily find the Matterhorn or the Cliffs of Moher to be beautiful, but there is beauty to be found in every piece of nature: a small pebble on the beach can have a beautiful shape, and even a wasteland can be beautiful (perhaps when one gets to understand that it involves an interestingly balanced ecosystem) - there is always some beauty to be found, if one looks carefully.

This thesis is very plausible and it certainly fits our everyday aesthetic experiences of nature. When it comes to photographs or other types of works of art, like paintings, the claim is that these can have negative as well as positive aesthetic properties, since - unlike nature they are created in an intentional way by an artist, and that the artist might fail in her deed: her

\footnotetext{
${ }^{18}$ This is a neighbouring, but stronger, claim than the idea that the appreciator of nature (not landscapes) is an "active participant" (for a good discussion of this claim, see Budd (2002, Chap.4, §2)). Also, compare to Brady (1998, p.142): "With art, much depends on the ability of the artist to create an engaging and imaginative work of art. With nature, the character of the natural object to a great extent determines how much perceptual effort is required. It may take less effort to see the beauty of a particularly grand landscape than a mudflat or a wasteland. However, mudflats and wastelands may also have aesthetic value, and perceiving that is dependent upon the effort of the percipient." (Brady of course does not use here the terms "nature" and "landscape" in the way I do.)
} 
intentions might be uninteresting or boring, or they can be badly executed, and the resulting artwork might thus be judged to be unpleasant or otherwise aesthetically negatively evaluated. In the case of nature, this cannot happen simply because there were no intentions in the first place, so there can be no uninteresting or boring intentions, and no failure in their execution. Now, quite obviously, given the understanding of the nature and the appreciation of landscapes from the preceding sections, where a landscape, unlike nature ${ }^{19}$, comes into being via an interaction with an observer - the 'artist' - when she chooses, at the very least, a point of view, a framing, and a time of observation, there is then room for bad choices and failure. As we have seen, aesthetic properties of landscapes (as of all objects of aesthetic appreciation) are grounded in their non-aesthetic properties. These include the context of creation, that is, a point of view, a framing, and a time of observation - thus, they include such-and-such sensory properties rather than others - and they also include non-sensory properties based in the taste of the evaluator, the information she has, and the way she uses her imagination; all of which can be triggered and guided by the 'creator' of the landscape (by the kind of choices mentioned above, or by the information she provides). Aesthetic properties of a landscape are then grounded in this variety of non-aesthetic properties, where some of them are in the power of the creator of the landscape to influence, and there is then the same type of possibility of failure as in the case of artworks like photographs or paintings. Landscapes, in this sense, are like works of art - and very peculiar works of art indeed, since the artist always necessarily coincides with the spectator ${ }^{20}$.

\footnotetext{
19 Budd (2002, p.91): "[...] just as the aesthetic appreciation of art is the appreciation of art as art, so the aesthetic appreciation of nature is the aesthetic appreciation of nature as nature. For, given that the natural world is not anyone's artefact, the aesthetic appreciation of nature as nature, if it is to be true to what nature actually is, must be the aesthetic appreciation of nature not as an intentionally produced object (and so not as art)."

${ }^{20}$ This notion of the artist/creator can of course be understood as applying in degree. An appreciator of a landscape can take the time and effort to appreciate a landscape in the best possible way (say, for instance, by hiking up a mountain opposite to the Matterhorn during the night, in order to be there at sunrise, at the best time of the year, and so on), but she can also be a 'minimal creator' when, for instance, she just looks out a train's window to appreciate the mountains that just happen to be there - this is a very minimal effort, but one that still counts as 'creation' in a minimal sense, where the appreciator has simply made the choice to pay attention to what is there, given the point of view and the framing she has. Also, the artist/creator can, of course, be educated by other artists/creators. A good mountain guide, or a guide in, say, the Arches National Park, is typically someone who teaches her clients when, where, and how to look at a landscape, as well as how to understand it, providing information along with the best points of view and the best time of observation.
} 


\section{Acknowledgments:}

For very useful comments that helped me to improve this article, I would like to thank Lynda Gaudemard, Baptiste Le Bihan, Jerrold Levinson, Olivier Massin, and Anne Meylan.

\section{References:}

BENOVSKY, J. 2011. "Three kinds of realism about photographs". The Journal of Speculative Philosophy, 25:4

BENOVSKY, J. 2012a. "Photographic Representation and Depiction of Temporal Extension". Inquiry Vol.55, No.2, 194-213.

BENOVSKY, J. 2012b. "Aesthetic Supervenience vs. Aesthetic Grounding". Estetika: The Central European Journal of Aesthetics, XLIX/V, No.2, 166-178

BENOVSKY, J. 2013. "Experiencing photographs qua photographs: what's so special about them?" Contemporary Aesthetics

BENOVSKY, J. 2014. "The limits of photography". International Journal of Philosophical Studies, Vol.22, Issue 5, p.716-733.

BENOVSKY, J. forthcoming. "From experience to metaphysics: on experience-based intuitions and their role in metaphysics". Noûs, DOI: 10.1111/nous.12024.

BENOVSKY. J. manuscript. "Depiction, imagination, and photography".

BRADY, E. 1998. "Imagination and the aesthetic appreciation of nature". The Journal of Aesthetics and Art Criticism, 56:2.

BUDD, M. 2002. The Aesthetic Appreciation of Nature. Oxford University Press.

BURKE, E. 1757. A Philosophical Enquiry into the Origin of Our Ideas of the Sublime and Beautiful. Oxford University Press, new edition 2015.

CARLSON, A. 1981. "Nature, Aesthetic Judgment, and Objectivity". Journal of Aesthetics and Art Criticism 40(1):15-27.

CARLSON, A. 1984. "Nature and Positive Aesthetics". Environmental Ethics, 6: 5-34.

CARLSON, A. 2000. Aesthetics and the environment. Routledge.

CAROLL, N. 1993. "On being moved by nature: between religion and natural history". In Landscape, Natural Beauty and the Arts, Kemal, S. and Gaskell, I. (eds.), Cambridge University Press.

FUDGE, R. S. 2001. "Imagination and the science-based aesthetic appreciation of unscenic nature". The Journal of Aesthetics and Art Criticism, 59:3.

HELLER, M. 1990. The ontology of physical objects: four-dimensional hunks of matter. Cambridge University Press.

HELLER, M. 2008. "The Donkey Problem", Philosophical Studies 140(1):83-101. 
HEPBURN, R. W. 1963. "Aesthetic appreciation of nature". British Journal of Aesthetics 3(3):195209.

KANT, I. 1790. Critique of Judgment. trans. Werner Pluhar, Indianapolis: Hackett, 1987.

LEVINSON, J. 1984. "Aesthetic Supervenience". Southern Journal of Philosophy 22, Supplement 93-110.

LEVINSON, J. 2015. "Paintings, photographs, titles", in Matravers and Freeman (eds.), Figuring Out Figurative Art. Contemporary Philosophers on Contemporary Paintings. Routledge.

MERRICKS, T. 2001. Objects and Persons. Oxford University Press.

PARSONS, G. 2002. "Nature Appreciation, Science, and Positive Aesthetics". British Journal of Aesthetics 42 (3):279-295.

PAUL, L. A. 2010. Temporal Experience. Journal of Philosophy 107 (7).

ROLSTON, H. 1995. "Does aesthetic appreciation of landscapes need to be science-based?", British Journal of Aesthetics, 35:4.

SCHOPENHAUER, A. 1818. The World as Will and Representation. trans. Norman, J., Welchman, A., Cambridge University Press.

UNGER, P. 1979. "There are no ordinary things". Synthese 41(2):117-154.

VAN INWAGEN, P. 1990. Material Beings. Cornell University Press.

WALTON, K. L. 1970. "Categories of Art". Philosophical Review 79(3):334-367.

WALTON, K. L. 1984. "On the Nature of Photographic Realism". Critical Inquiry 11:2.

WALTON, K. L. 1990. Mimesis as Make-Believe: On the Foundations of the Representational Arts. Harvard University Press.

ZANGWILL, N. 2001. The metaphysics of beauty. Cornell University Press. 